\title{
Clinical evaluation of clobetasone butyrate: a comparative study of its effects in postoperative inflammation and on intraocular pressure
}

\author{
T. G. RAMSELL, 1 R. S. BARTHOLOMEW, ${ }^{2}$ AND S. R. WALKER ${ }^{3}$ \\ From the ${ }^{1}$ Wirral Ophthalmic Unit, Birkenhead General Hospital, Birkenhead, Merseyside, \\ ${ }_{2}^{2}$ Princess Alexandra Eye Pavilion, Chalmers Street, Edinburgh, and ${ }^{3}$ Medical Division, Glaxo Group \\ Research Ltd., Greenford, Middlesex
}

SUMMARY Clobetasone butyrate, a new corticosteroid with a high topical activity, has been compared with prednisolone phosphate and a placebo in the treatment of inflammation following cataract extraction. These 2 steroids were more effective in relieving postoperative inflammation than placebo $(\mathrm{P}<0.05)$, though no obvious clinical differences between the 2 compounds emerged from this investigation. However, a single-blind comparative study against betamethasone phosphate in patients suspected of having steroid-induced glaucoma showed that, while betamethasone phosphate significantly raised intraocular pressure, clobetasone butyrate had only a minimal effect, and this difference was statistically significant $(P<0.02)$.

For more than 25 years corticosteroids applied locally have been used to suppress various types of ocular inflammation. However, although steroids have been used postoperatively to decrease inflammation following elective cataract extractions, their role remains controversial. Some ophthalmologists use them routinely, others when there is an unusual amount of inflammation, and a third group only rarely. Also among those who use this type of treatment there were wide variations in the frequency of application of the medication. However, one of the main disadvantages of steroid therapy is the production of steroid-induced glaucoma in certain individuals (Armaly, 1966), and this may be related either to the compound itself or to the concentration of 'available' steroid (Ramsell et al., 1967).

The inflammation following surgical trauma provides a potential model for comparing the ability of steroids to reduce inflammation. Only 3 controlled studies have been published in this condition (Burde and Waltman, 1972; Mustakallio et al., 1973; Corboy, 1976), and in the first 2 of these no difference in the resolution of the inflammation was found between steroid and placebo treated patients. However, Corboy found a statistically significant difference in favour of betamethasone phosphate used 5 times daily when compared with placebo.

Address for reprints: Mr T. G. Ramsell, Wirral Ophthalmic Unit, Birkenhead General Hospital, Birkenhead, Merseyside
Clobetasone butyrate, unlike betamethasone phosphate and prednisolone phosphate, is a steroid with a high cutaneous topical activity, as has been shown by its successful use in the treatment of inflammatory dermatoses (Munro and Wilson, 1975). It was postulated that because of this superior topical activity it might prove to be effective in the local treatment of external eye diseases. However, as it is also more lipid-soluble than either prednisolone phosphate or betamethasone phosphate it might therefore penetrate the epithelial layer of the cornea more readily and hence have a better therapeutic effect in intraocular inflammation.

The aims of the present investigation were to evaluate the anti-inflammatory activity of clobetasone butyrate and to assess its effect on intraocular pressure. A controlled study, with prednisolone phosphate and placebo as comparative groups, was therefore carried out in the treatment of postoperative inflammation. By including these 2 control groups it was hoped to determine whether this trial might provide a good model for the clinical evaluation of the steroids used in ophthalmology.

\section{Patients and methods}

CLINICAL STUDY

Fifty-seven patients who had uncomplicated intracapsular cataract extraction were selected for study. After operation they were treated twice daily for the 
first 4 days with chloramphenicol $(0 \cdot 5 \%)$ only. At the end of this treatment period they were randomly allocated to clobetasone butyrate $(0 \cdot 1 \%)$, prednisolone phosphate $(0.5 \%)$, or a placebo preparation (vehicle only) in such a way that the clinical comparison was double-blind. All preparations were administered as $\mathbf{2}$ drops 4 times a day for the whole period of the study, and the chloramphenicol drops were also continued.

Patients were assessed by the same observer for postoperative inflammation on the 4th, 6th, and 10th (discharge) days and again 2 and 6 weeks after discharge. Inflammation was assessed by observation of the following factors: (a) Conjunctival injection was scored as absent (0), mild (1), moderate (2), or severe (3). Assessment was made for both bulbar (4 quadrants separately) and tarsal conjunctiva. (b) The degree of discomfort was ascertained by questioning the patients and was recorded on a 0 to 3 scale. (c) Complications were noted as either present (a score of 2) or absent (0), and these were: (i) striate keratitis, (ii) hyphaema, (iii) iritis. In addition, on the 10th postoperative day the surgeon (T. G. R.) gave his overall impression of the treatment as excellent, good, satisfactory, or poor.

\section{INTRAOCULAR PRESSURE STUDY}

Four patients who were suspected of having steroidinduced glaucoma were selected for a single-blind within-subject investigation comparing clobetasone butyrate with betamethasone phosphate. The intraocular pressure was measured, and in 2 of the 4 patients both eyes were studied. The patients were asked to instil betamethasone phosphate, $0 \cdot 1 \%$ (treatment 1) 2 drops 4 times a day into the eye under investigation for a period of up to 6 weeks. During this time they were seen at two-weekly intervals, when their intraocular pressures were recorded. A 4-week period followed during which time no eyedrops were instilled and their intraocular pressures were allowed to return to their usual resting values. Then clobetasone butyrate, $0.1 \%$ (treatment 2 ) was instilled, 2 drops 4 times a day, for up :o 6 weeks. Again intraocular pressures were measured at 2-weekly intervals. If, however, during the study the pressure rose more than $10 \mathrm{~mm}$ after 4 weeks the treatment was discontinued.

\section{Results}

\section{CLINICAL STUDY}

Fifty-seven patients ( 43 female, 14 male) between the ages of 49 and 90 years entered the study. Twenty patients (17 female, 3 male; age range 49 to 85 years) received clobetasone butyrate; 18 (13 female, 5 male; age range 66 to 90 years) received

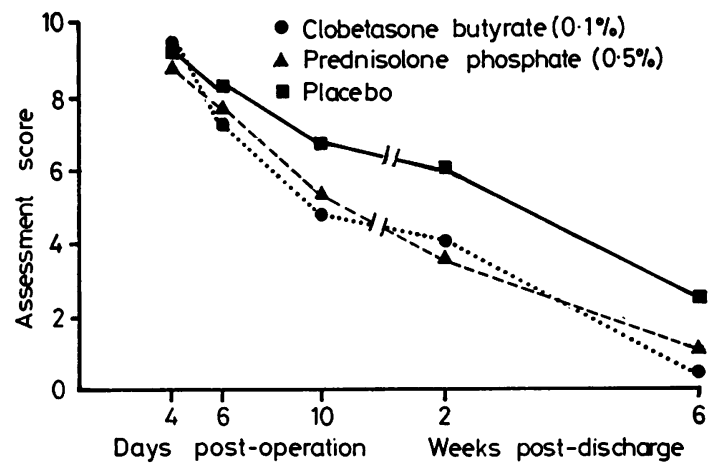

Fig. 1 Results of treatments determined by total assessment score with respect to time

prednisolone phosphate, and 19 (13 female, 6 male, age range 49 to 87 years) received a placebo. The groups were found to be matched with respect to age, sex, and initial severity of inflammation.

Fig. 1 shows the results of the 3 treatments as determined by the total assessment score with respect to time. Clobetasone butyrate and prednisolone phosphate were clinically more effective in relieving postoperative inflammation than the placebo, and the difference reached statistical significance (chisquared test, $\mathrm{P}<0.05$ ) on the 10th postoperative day and 2 weeks after discharge. However, there was no obvious difference between the 2 steroids after these time periods, and no difference between any of the 3 preparations was seen 6 weeks after discharge.

These results were confirmed by the surgeon's overal! impression on the 10th postoperative day (Table 1). Nine patients receiving clobetasone butyrate and 7 receiving prednisolone phosphate obtained an excellent or good response, whereas 17 patients receiving placebo had only a satisfactory or poor response (chi-squared test, $P<0.05$ ).

INTRAOCULAR PRESSURE STUDY

This group of 4 patients (Table 2) were all intermediate steroid responders with pressure rises of between 6 and $16 \mathrm{mmHg}$ following provocation with

Table 1 Surgeon's overall assessment of postoperative inflammation

\begin{tabular}{llllll}
\hline Treatment & Excellent & Good & Satisfactory & Poor & Total \\
\hline Clobetasone butyrate & 1 & 8 & 7 & 4 & 20 \\
$\begin{array}{l}\text { Prednisolone } \\
\text { phosphate }\end{array}$ & 3 & 4 & 7 & 4 & 18 \\
$\begin{array}{l}\text { Placebo } \\
\begin{array}{l}\text { Steroids superior to placebo: } \\
\text { P }\end{array}\end{array}$ & 1 & 0.05 (chi-squared test) & 19 \\
\hline
\end{tabular}


Table 2 Comparative effect of clobetasone butyrate and betamethasone phosphate on intraocular pressure

\begin{tabular}{|c|c|c|c|c|c|c|c|c|c|c|c|c|c|c|}
\hline \multirow{4}{*}{$\begin{array}{l}\text { Patient } \\
\text { no. }\end{array}$} & \multirow{4}{*}{$\begin{array}{l}\text { Age } \\
61\end{array}$} & \multirow{4}{*}{$\begin{array}{l}\text { Sex } \\
\text { F }\end{array}$} & \multirow{4}{*}{$\begin{array}{l}\begin{array}{l}\text { Eye } \\
\text { studied }\end{array} \\
\text { Right }\end{array}$} & \multicolumn{11}{|c|}{ Intraocular pressure (rise) } \\
\hline & & & & \multicolumn{5}{|c|}{ Betamethasone phosphate (q.d.s.) } & \multicolumn{6}{|c|}{ Clobetasone butyrate (q.d.s.) } \\
\hline & & & & \multirow{2}{*}{$\begin{array}{l}0 \\
19\end{array}$} & \multicolumn{2}{|c|}{2 weeks } & 4 weeks & 6 weeks & \multirow{2}{*}{$\begin{array}{l}0 \\
22\end{array}$} & \multicolumn{2}{|c|}{2 weeks } & \multicolumn{2}{|c|}{4 weeks } & 6 weeks \\
\hline & & & & & 24 & (5) & 30 (11) & - & & 22 & $(0)$ & 21 & $(-1)$ & 25 (3) \\
\hline 2 & 57 & $\mathbf{F}$ & Right & 18 & 19 & (1) & $23(5)$ & $25(7)$ & 17 & 17 & (0) & 21 & (4) & 20 \\
\hline 3 & 68 & $\mathbf{M}$ & $\begin{array}{l}\text { Right } \\
\text { Left }\end{array}$ & $\begin{array}{l}22 \\
22\end{array}$ & $\begin{array}{l}24 \\
26\end{array}$ & $\begin{array}{l}\text { (2) } \\
\text { (4) }\end{array}$ & $\begin{array}{ll}27 & (5) \\
27 & (5)\end{array}$ & $\begin{array}{ll}30 & (8) \\
31 & (9)\end{array}$ & $\begin{array}{l}23 \\
23\end{array}$ & $\begin{array}{l}23 \\
22\end{array}$ & $\begin{array}{l}(0) \\
(-1)\end{array}$ & $\begin{array}{l}23 \\
22\end{array}$ & $\begin{array}{l}(0) \\
(-1)\end{array}$ & $\begin{array}{ll}24 & \text { (1) } \\
24 & \text { (1) }\end{array}$ \\
\hline 4 & 57 & $\mathbf{F}$ & $\begin{array}{l}\text { Right } \\
\text { Left }\end{array}$ & $\begin{array}{l}18 \\
18\end{array}$ & $\begin{array}{l}23 \\
23\end{array}$ & $\begin{array}{l}(5) \\
(5)\end{array}$ & $\begin{array}{l}28 *(10) \\
29 *(11)\end{array}$ & - & $\begin{array}{l}19 \\
21\end{array}$ & & $\begin{array}{l}(-1) \\
(1)\end{array}$ & & $\begin{array}{l}(-1) \\
(1)\end{array}$ & $\begin{array}{ll}19 & (0) \\
21 & (0)\end{array}$ \\
\hline Mean rise & & & & & & 4 & 8 & 8 & & & 0 & & 1 & 1 \\
\hline
\end{tabular}

- At 5 weeks

steroids. The mean rise in intraocular pressure over a period of 4 to 6 weeks with betamethasone phosphate $(0 \cdot 1 \%)$ was $8 \mathrm{mmHg}$ (range 5 to $11 \mathrm{mmHg}$ ), whereas with clobetasone butyrate $(0 \cdot 1 \%)$ the mean rise over a similar period was only $1 \mathrm{mmHg}$ (range 0 to $4 \mathrm{mmHg}$ ). This difference is statistically significant at 4 weeks (paired $t$ test, $\mathrm{P}<0.02$ ).

\section{Conclusion}

In spite of the vast clinical experience and experimental work with locally applied corticosteroids the relative potencies of various steroids used in ophthalmology have not been evaluated from clinical investigations. Our work confirms that of Corboy (1976) and indicates that postoperative inflammation is a suitable model for the assessment of the potency of corticosteroids. Previous investigators who have come to the opposite conclusion have perhaps done so either because they used a weaker steroid such as hydrocortisone or did not apply the more potent agent sufficiently frequently.

Clobetasone butyrate is an effective steroid in reducing postoperative inflammation and is comparable in efficacy to prednisolone phosphate. It is of interest that our studies have shown that clobetasone butyrate has only a minimal effect on intraocular pressure when compared with betamethasone phosphate in patients known to experience steroid- induced glaucoma. It is therefore of some significance that with clobetasone butyrate it has been possible to dissociate the adverse intraocular pressure effect from the advantageous antiinflammatory effects, and thus we may well have a 'safer' steroid for use in ophthalmology.

The authors wish to thank Miss Susan Bristow for typing this paper.

\section{References}

Armaly, M. F. (1966). In Drug Mechanisms in Glaucoma: the Gilston Glaucoma Symposium, pp. 191-229. Edited by G. Paterson, S. J. H. Miller, and G. D. Paterson. Churchill: London.

Burde, R. M., and Waltman, S. R. (1972). Topical corticosteroids after cataract surgery. Annals of Ophthalmology, 4, 290-293.

Corboy, J. M. (1976). Corticosteroid therapy for the reduction of postoperative inflammation after cataract extraction. American Journal of Ophthalmology, 82, 923.

Munro, D. D., and Wilson, L. C. (1975). Clobetasone butyrate, a new topical corticosteroid: clinical activity and effects on pituitary-adrenal axis function and model of epidermal atrophy. British Medical Journal, 626-628.

Mustakallio, A., Kaufman, H. E., Johnston, G., Wilson, R. S., Roberts, M. D., and Harter, J. C. (1973). Corticosteroid efficacy in postoperative uveitis. Annals of Ophthalmology, 5, 719-730.

Ramsell, T. G., Trillwood, W., and Draper, G. (1967). A trial of the effects of prednisolone phosphate eye drops on the intraocular pressure of normal volunteers. British Journal of Ophthalmology, 51, 398-402. 